\title{
Aplikasi Digitalisasi Seni Bela Diri Silat Tradisional Minangkabau
}

\section{Minangkabau Traditional Silat Martial Arts Digitization App}

\author{
Tri Lestari, Taufik Gusman, Defni \& Muhammad Yosazikri Ikhsan
}

Jurusan Teknologi Informasi Politeknik Negeri Padang Kampus Limau Manis Padang 25163 Telp.0751-72590 Fax.0751-72576 Email : trilestari@pnp.ac.id, taufikgusman@pnp.ac.id, defni@pnp.ac.id, yosa.zikri2@gmail.com

\begin{abstract}
Minangkabau traditional martial arts digitization app is an android game-shaped application created to display minangkabau silat using 3-Dimensional (3D) animation technology. This app will convert materials and illustrations into 3D animated shapes that can be played using the android app so that it will attract users to more easily understand and understand about minangkabau silat. The data that is made as a necessity for application is obtained from literature studies and field studies by using interview techniques with silat officials in Padang city. For the creation of this game application using virtual reality technology and the tools used are 3 Dimensional blender and Unity Game Engine.
\end{abstract}

Keywords : Silek Minangkabau, Virtual Reality, 3-Dimensional Animation

\section{PENDAHULUAN}

Minangkabau merupakan salah satu suku di Indonesia yang memiliki keragaman budaya, adat, dan kesenian. Salah satu warisan budaya Minangkabau yang terkenal ialah silat atau dalam Bahasa minang disebut dengan silek. Seni beladari ini diciptakan dengan tujuan sebagai pertahanan diri dan pertahanan wilayah, serta sebagai sarana pendidikan pembentukan karakter masyarakat. Terdapat banyak aliran/jenis silat yang berkembang di Ranah Minangkabau. Hal ini dipengaruhi oleh kultur budaya dan kebiasaan serta juga tipografi dari kondisi masyarakat yang ada di wilayah tersebut. Di Minangkabau aliran silat ini dikenal dengan aliran silat tuo yaitu kumango, harimau, langkisau dan taralak (sitarlak). Selama ini masyarakat dapat mengenal aliran silat yang ada di Minangkabau baik melalui perguruan silat, buku maupun lewat platform terbesar video seperti youtube, metube dan lain sebagainya.

Perguruan silat yang ada di Minangkabau tetap melestarikan budaya dengan tetap mempertahankan silat daerah tetapi kebanyakan perguruan silat ini hanya diisi oleh orang-orang yang berminat dalam pecak silat tradisional ini. Bagi masyarakat yang tidak berminat terutama dikalangan anak muda maka mereka kebanyakan tidak terlalu mengenal aliran silat dan gerakan silat yang ada di minangkabau padahal silat di Minangkabau merupakan sebuah warisan budaya yang sudah terkenal sampai ke luar negeri. Banyaknya masyarakat terutama remaja tidak terlalu mengenal tentang aliran dan gerakan silat di Minangkabau hal ini diakibatkan karena jika mereka mau menggali informasi tentang silat ini harus ke perguruan silat tersebut ataupun menontonnya lewat aplikasi platform video terbesar di dunia seperti youtube dan lain sebagainya. Untuk masyarakat yang memanfaatkan aplikasi platform video ini terkadang tidak terlalu menarik bagi kaum remaja untuk melihatnya dikarenakan video yang tampil dari aplikasi tersebut tidak terlalu detail menampilkan aliran dan gerakan silat yang ada di Minangkabau.

Dengan kemajuan teknologi informasi terutama di bidang multimedia yang dapat menjadikan sebuah media lebih 
interaktif, maka dibuatlah usaha-usaha untuk lebih memperkenalkan aliran dan gerakan silat ini kepada masyarakat terutama untuk kaum remaja agar lebih tertarik untuk melihatnya. Salah satu cara yang dapat ditempuh untuk lebih memperkenal tentang silat ini kepada kaum remaja adalah dengan membuat sebuah aplikasi yang menggunakan konsep virtual reality. Pengubahan aliran dan gerakan silat dalam bentuk virtual reality akan dapat menarik bagi kaum remaja untuk lebih mengenal tentang silat yang ada di Minangkabau dikarenakan tampilan dan fiturnya yang lebih interaktif. Berdasarkan hal tersebut dibuatlah sebuah tugas akhir ini akan membuat aliran dan gerakan silat yang ada di Minangkabau dalam bentuk virtual reality. Fitur -fitur yang ada dalam aplikasi ini akan lebih interaktif dengan pengguna sehingga pengguna tidak merasa cepat bosan dalam menonton aliran dan gerakan silat ini dan akan lebih menggali inofrmasi seputar silat itu sendiri. Selain lebih menarik minat pengguna untuk melihat virtual reality aliran dan gerakan silat ini juga dapat menjadi salah satu promosi budaya Minangkabau sehingga akan lebih lagi memperkenalkan silat ini ke masyarakat.

\section{Virtual Reality}

Virtual Reality (VR) merupakan istilah yang digunakan untuk menggambarkan lingkungan virtual yang dihasilkan komputer yang dapat dipindahkan dan dimanipulasi oleh pengguna secara real time. Teknologi ini membuat pengguna atau user berinteraksi dengan dan merasa berada di lingkungan tersebut. Menurut M. Mihelj et al. Virtual reality dipahami sebagai simulasi komputer interaktif yang dapat mempengaruhi indra pengguna bahkan menggantikan satu atau lebih indra manusia, sehingga pengguna larut dalam lingkungan simulasi (virtual environment) (Mihelj, Novak, \& Beguš, 2014). Istilah virtual reality pertama kali muncul pada tahun 1989 pada beberapa majalah yang diterbitkan oleh Jaron Lanier selaku pendiri VPL Research Company. Virtual reality ini menggunakan komputer dan teknologi elektronik untuk menghasilkan hasil tampilan 3-Dimensi yang nyata, dapat disentuh, dan didengar dengan bantuan perangkat seperti kacamata VR, sarung tangan VR, serta perangkat lain yang menggunakan sensor terhadap lingkungan virtual. (Liu, 2012). Contoh dari penerapan teknologi VR ditampilkan pada Gambar 1.

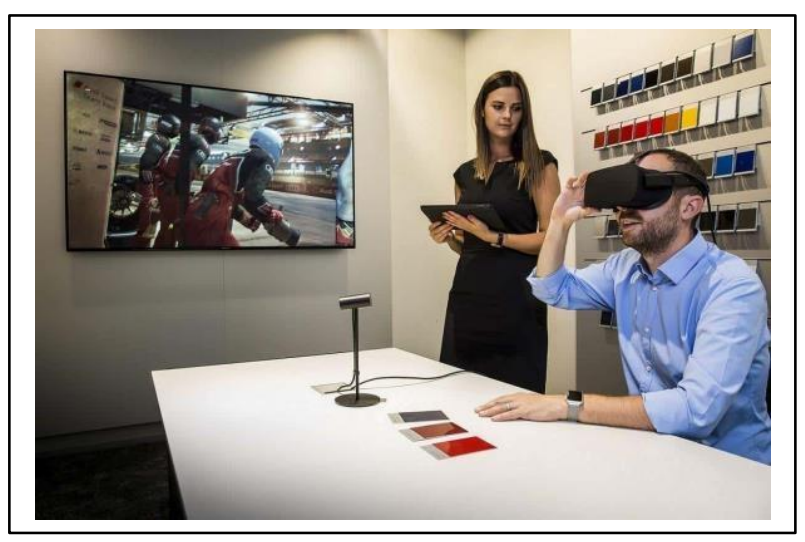

Gambar 1. Contoh Penerapan Teknologi VR

VR memiliki tiga karakteristik utama, yaitu interactivity, imagination, dan illution of immersion (Muttelein, 2018). Kunci utama dari ketiga karakter ini ialah interaksi penuh dari user dan sistem Sistem VR harus membuat user merasakan lingkungan virtual seperti lingkungan yang nyata. Untuk mencapai tujuan tersebut, sistem VR harus menyediakan kemampuan persepsi manusia, termasuk penglihatan, pendengaran, sentuhan bahkan rasa dan penciuman. Sistem VR dapat menyediakan sarana interaksi manusia dan komputer yang nyaman. Dengan cara ini user dapat mengoperasikan lingkungan virtual secara real time, mendapatkan informasi dan umpan balik data dari lingkungan virtual. Selain itu, waktu memrosesan juga sangat penting, jika terjadi delay saat interaksi, akan menyebabkan user sulit merasakan pengalaman psikologis yang sama dengan lingkungan virtual. Sehingga dibutuhkan 
waktu pemrosesan yang cepat dalam teknologi virtual reality.

Virtual Reality membuat waktu, ruang dan informasi semakin luas. Hal-hal yang tidak dapat ditampilkan secara nyata dapat ditampilkan secara virtual. Menurut jenis teknologinya VR mancakup beberapa aspek (Liu, 2012), yaitu:

a. Teknologi Citra Panoramik ialah perkembangan seni visual dalam pemrosesan citra. Teknologi ini mengambil objek dengan pengambilan gambar $360^{\circ}$, sehingga keseluruhan objek dapat terlihat secara detail. Citra panoramik ini bukan merupakan teknologi VR nyata, tetapi teknologi ini bisa memberikan kesan nyata dan nuansa interaktif kepada user.

b. Teknologi 3-Dimensi merupakan teknologi inti dari virtual reality. Dalam mensimulasikan fungsi visual secara real dan nyata, sangat bergantung pada teknologi tampilan 3Dimensi dan teknik pemrosesan citra. Tiga Dimensi (3D) adalah sebuah objek / ruang yang memiliki panjang, lebar dan tinggi yang memiliki bentuk. Istilah ini biasanya digunakan dalam bidang seni, animasi, komputer dan matematika. Setiap bangun tiga dimensi memiliki kapasitas, disebut juga dengan volume.

c. Teknologi Stereo sound display adalah penghubung penting untuk mendapatkan teknologi virtual reality yang baik. Audio pada virtual reality bukan hanya stereo biasa, tetapi teknologi suara 3D yang lebih tinggi yang diwujudkan melalui head sound technology yang dapat mensimulasikan karakteristik fisik suara dunia nyata. Lingkungan virtual suara 3D memungkinkan user untuk membedakan jarak mereka, dan menentukan lokasi sumber suara. Suara 3D dalam ruang tiga dimensi virtual dapat direfleksikan di permukaan model 3D. d. Teknologi Interaktif dalam teknologi VR sangatlah penting dan membuat teknologi ini menjadi menarik. Saat ini, teknologi interaktif meliputi tiga macam: interaksi lokasi spasial, interaksi perubahan lingkungan dan interaksi perilaku tiga dimensi. Teknologi interaktif meningkatkan kehidupan dan jiwa dunia VR.

Saat berada dalam lingkungan virtual, pengguna akan merasa seolah menyatu dengan dunianya dan dapat berinteraksi dengan objek-objek yang ada di sana. Hal ini disebut dengan telepresence. Telepresence diartikan sebagai pengalaman keberadaan seseorang terhadap lingkungan melalui sebuah media (Moura, 2017). Penggunaan istilah telepresence digunakan untuk jenis komunikasi yang menggunakan media dalam tujuannya menghadirkan persepsi. Steuer menjelaskan dua indikator utama dalam menjabarkan komunikasi melalui media dalam kaitannya terhadap telepresence yaitu vividness dan interactivity (Steuer, 1993).

Vividness merupakan indikator dari sebuah media yang dapat meningkatkan persepsi. Vividness berarti kualitas representasional dari lingkungan yang memberikan informasi melalui indra. Menurut Steuer(1993), ada dua komponen dalam telepresence, yaitu Depth of information dan Breadth of information. Depth of information yaitu banyaknya kualitas data yang ditansfer demi menciptakan lingkungan VR (resolusi, ketajaman gambar), sedangkan Breadth of information merupakan seberapa besar indera pengguna dimanipulasi, umumnya pada penglihatan dan pendengaran.

Interaktifitas merupakan penjelasan tentang pada bagian mana pengguna dapat berpartisipasi untuk merubah bentuk dan isi dari sebuah media. Tiga faktor yang berkontribusi kepada interaktifita yaitu Speed of interaction, or response time: kecepatan, yang mengacu 
pada tingkat di mana input dapat berasimilasi dengan lingkungan termediasi. Range kisaran yang mengacu pada jumlah kemungkinan tindakan pada waktu tertentu. Mapping yaitu pemetaan, yang mengacu pada kemampuan sistem untuk memetakan kontrol untuk perubahan lingkungan yang termediasi secara alami dan dapat diprediksi.

\section{Silat Tradisional Minangkabau}

Silek Minangkabau berbeda dari pencak silat dan silat pada umumnya. Kata "silek" dalam Bahasa Minangkabau tidak persis sama padanannya dengan kata "silat" dalam Bahasa Indonesia. Silek bukan olahraga (permainan) ketangkasan menyerang dan membela diri atau sebuah art martial 'seni bela diri' sebagaimana pengertian silat dalam berbagai referensi, tentang silat, yaitu terdiri atas "pencak" dan "silat", yaitu: pencak adalah gerakan bela diri tanpa lawan dan silat adalah gerakan bela diri yang tidak bisa dipertandingkan. Silat minangkabau ditampilkan pada Gambar 2.

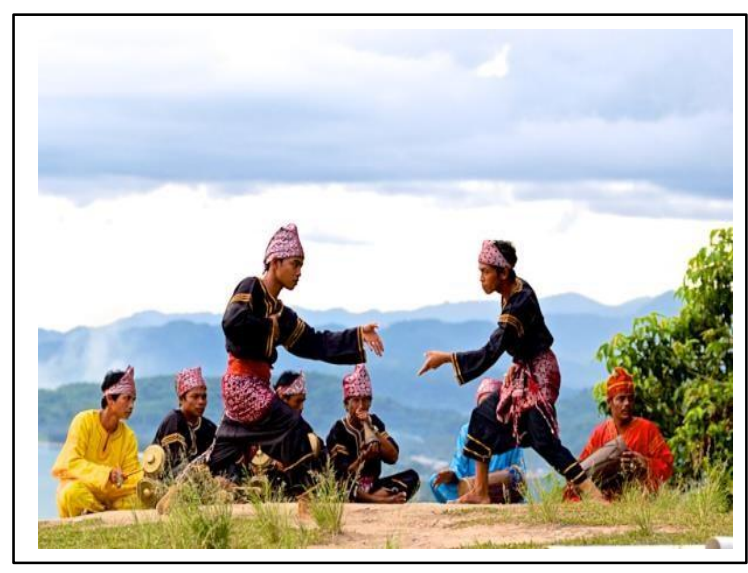

Gambar 2. Silat Minangkabau (Irfan, 2013)

Silat ini diwariskan di tanah Minangkabau, Sumatra Barat, Indonesia. Secara turun temurun, masyarakat Minangkabau memiliki kebiasaan merantau sejak ratusan tahun yang lalu. Dengan merantau tentu saja mereka harus memiliki keterampilan menjaga diri dari hal-hal buruk selama berada di rantau., misalnya dirampok atau diserang orang yang tak di kenal. Di samping itu juga, silat penting untuk mempertahankan daerah kampung halaman terhadap ancaman dari luar. Silat Minangkabau juga dapat di aplikasikan sebagai sarana hiburan yang berpadukan dengan drama yang disebut Randai. Randai berisikan nasehat dan petuah dari nenek moyang yang diturunkan secara turun temurun.

Terdapat berbagai jenis silat minangkabau, diantaranya:

Silek Harimau merupakan aliran yang paling menonjol di silek Minangkabau. Disebut Silat Harimau karena memiliki gerakan yang menyerupai gerakan harimau, selain itu gerakan awal atau kudakuda gerakan silat ini menggunakan gaya seperti harimau. Ada mitos yang menceritakan jika pesilat dapat menguasai aliran ini, maka mereka dapat berubah wujud menjadi harimau. Namun belum diketahui kapan dan siapa yang mencetus Silat Harimau ini. Karena silat ini dikisahkan secara lisan saja, akibatnya tidak tercatat dalam sejarah mengenai kapan silat ini di cetuskan. Silat Harimau juga memiliki karakteristik yang tegas dan keras layaknya harimau. Para pelajar yang akan mempelajari silat ini di didik terlebih dahulu untuk memantapkan hati dan pikiran mereka. Agar makna dan pengertian mengenai Silat Harimau sendiri tidak salah jalan.

Silek Pauh merupakan aliran silat termuda dari sepuluh aliran utama silat Minangkabau yang berasal dari Kota Padang. Pada zaman pra kemerdekaan, daerah Pauh V dan Pauh IX yang terletak di pinggiran Kota Padang (sebelum perluasan) adalah tempat berkumpul para pejuang yang menekan posisi penjajah Belanda. Pada zaman penjajahan, Belanda tidak terlalu mau mengurus wilayah Pauh ini karena mereka anggap daerah rawan. Sebenarnya di Pauh itu sendiri berkumpul berbagai macam aliran silat yang ada di Minangkabau karena merupakan basis perjuangan menghadapi Belanda. Aliranaliran yang ada di sana adalah sitaralak, kumango, lintau, dan silek tuo. Akibat 
pertemuan berbagai aliran ini terjadilah pengembangan aliran baru oleh para pendekar-pendekar di sana yang belakangan disebut dengan silek Pauah yang legendaris dan ditakuti di kawasan Kota Padang.

Silek Tuo merupakan aliran silat yang dianggap paling tua yang turun dari daerah Pariangan, Padang Panjang, tapi ada pendapat lain yang mengatakan bahwa silat ini mulanya dikembangkan oleh Tuanku Nan Tuo, salah seorang anggota Harimau Nan Salapan atau golongan paderi. Jika pendapat ini diterima, maka "Silat Tuo" di Minangkabau terinspirasi dari gerakan binatang seperti harimau, buaya dan kucing.

Silek Siratalak yaitu aliran silat keras dan kuat dari Minangkabau, dikembangkan oleh Ulud Bangindo Chatib (1865) dari Kamang (dekat Bukittinggi), Kabupaten Agam, berkembang sampai ke wilayah Sawahlunto. Ada pendapat yang mengatakan bahwa aliran ini dirancang untuk menghadapi gerakan Silat Tuo. Gerakan Silat Tuo terinspirasi dari gerakangerakan binatang seperti harimau, kucing, dan buaya. Karakter khas silat jenis ini adalah menyerang disaat lawan akan menyerang. Silat ini menyebar dan berkembang di Malaysia dan terus ke Amerika. Silek Lintau berasal dari daerah Lintau Buo Kab.Tanah Datar, Sumatera Barat. Silat ini merupakan silat yang terkenal di Minangkabau, dengan dasar Lahkah Ompek (Langkah Empat) dan ada juga dengan Langkah Duo Boleh(Dua Belas). Silat lintau memili guru silat di hampir 9 koto (daerah) di lintau yang masing-masingnya memiliki gaya tersendiri namun tetap berdasarkan langkah yang sama.

\section{Unity}

Aplikasi unity 3D adalah game engine merupakan sebuah software pengolah gambar, grafik, suara, input, dan lain-lain yang ditujukan untuk membuat suatu game, meskipun tidak selamanya harus untuk game. Unity dikembangkan oleh Unity Technologies, pertama kali diumumkan dan dirilis pada bulan Juni 2005 di Apple Inc. Worldwide Developers Conference sebagai mesin permainan OS Xeksklusif. Pada 2018, mesin telah diperpanjang untuk mendukung 27 platform. Mesin dapat digunakan untuk membuat game tiga dimensi dan dua dimensi serta simulasi untuk banyak platformnya.

Unity memberi pengguna kemampuan untuk membuat game dalam 2D dan 3D, dan mesin menawarkan API scripting utama di C\#, baik untuk editor Unity dalam bentuk plugin, dan game itu sendiri, serta fungsionalitas drag and drop. Sebelum C\# menjadi bahasa pemrograman utama yang digunakan untuk mesin, sebelumnya $\mathrm{C}$ mendukung Boo, yang telah dihapus dalam rilis Unity 5, dan versi JavaScript disebut UnityScript, yang sudah ditinggalkan pada bulan Agustus 2017 setelah rilis Unity 2017.1 mendukung C\#. Mesin memiliki dukungan untuk API grafis berikut: Direct3D pada Windows dan Xbox One; OpenGL di Linux, macOS, dan Windows; OpenGL ES di Android dan iOS; WebGL di web; dan API kepemilikan di konsol permainan video. Selain itu, Unity mendukung API Logam tingkat rendah di iOS dan macOS dan Vulkan di Android, Linux, dan Windows, serta Direct3D 12 di Windows dan Xbox One.

\section{Blender}

Blender merupakan software pengolah 3 dimensi (3D) untuk membuat animasi 3D, yang bisa dijalankan di windows, macintosh dan linux. Blender juga sama seperti software 3D pada umumnya seperti 3DS Max, maya dan lightwave, tetapi juga mempunyai perbedaan yang cukup mendasar seperti projek kerja di blender bisa dikerjakan dihampir semua software 3D komersial lainnya, tampilannya yang bisa diatur sesuka hati, mempunyai simulasi physics yang baik dan menggunakan uv yang lebih mudah. Blender juga dapat membuat game karena memilik Game Engine. 
Segala jenis properti 3D yang ada pada aplikasi dibuat menggunakan Blender, serta menggerakan karakter agar terlihat seperti orang melakukan gerakan silat juga dibuat menggunakan aplikasi ini.

\section{Visual Studio 2019}

Microsoft Visual Studio merupakan sebuah perangkat lunak lengkap (suite) yang dapat digunakan untuk melakukan pengembangan aplikasi, baik itu aplikasi bisnis, aplikasi personal, ataupun komponen aplikasinya, dalam bentuk aplikasi console, aplikasi Windows, ataupun aplikasi Web. Visual Studio mencakup kompiler, SDK, Integrated Development Environment (IDE), dan dokumentasi (umumnya berupa MSDN Library). Kompiler yang dimasukkan ke dalam paket Visual Studio antara lain Visual C++, Visual C\#, Visual Basic, Visual Basic .NET, Visual InterDev, Visual J++, Visual J\#, Visual FoxPro, dan Visual SourceSafe.

\section{Gyroscope Sensor}

Gyroscope merupakan sensor kecepatan angular yang digunakan untuk mengukur kecepatan rotasi dari suatu benda. Gyroscope berfungsi untuk mengukur atau menentukan orientasi suatu benda berdasarkan pada ketetapan momentum sudut, dengan kata lain gyroscope menentukan gerakan sesuai grafitasi yang dilakukan oleh pengguna.

\section{METODOLOGI}

Metode pada penelitian ini dimulai dari pengumpulan data, analisis system, desain sistem, dan implementasi. Keseluruhan metode ini ditampilkan pada Gambar 3.

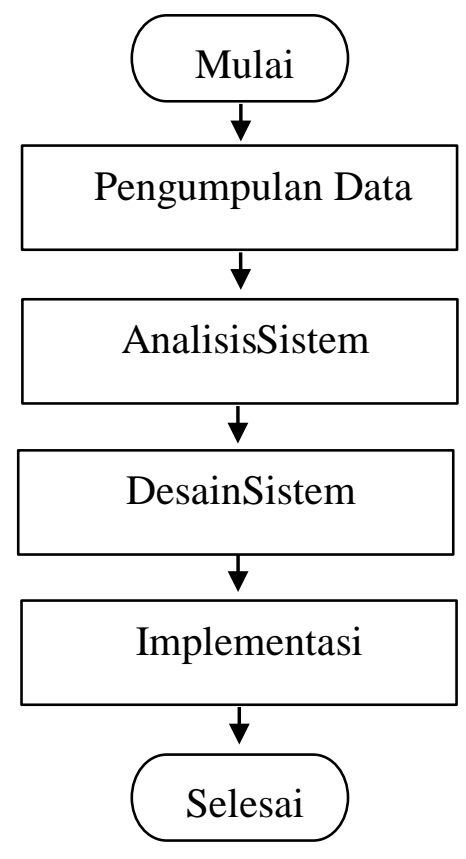

Gambar 3. Diagram Alir Metode Pembuatan Aplikasi Virtual Reality

Setiap tahapan pada metodologi ini akan dijelakan pada sub bab dibawah ini:

\section{Pengumpulan Data}

Metode pengumpulan data yang dilakukan dalam penelitian ini adalah:

a. Wawancara: Melakukan wawancara mengenai silat tradisional daerah minangkabau bersama narasumber yang merupakan salah satu tetinggi silat aliran "Silek Pauh" di kota Padang

b. Observasi: Melakukan observasi di Internet mengenai silat tradisional daerah minangkabau, dikarenakan sedang dalam kondisi pandemi.

\section{Analisis Sistem}

Analisis sistem bertujuan untuk memahami masalah yang sedang dihadapi dengan sistem yang ada saat ini, sehingga diharapkan dengan mengetahui masalahmasalah tersebut, kita bisa merancang suatu sistem baru yang akan menyelesaikan atau paling tidak mengurangi masalah-masalah yang ada. Analisis sistem ini nantinya akan memeriksa requirements apa yang harus 
dipenuhi oleh sistem baru yang akan dibangun tersebut.

\section{Desain Sistem}

Desain system pada pembuatan aplikasi VR ini terdiri dari desain flowchart aplikasi ditampilkan pada Gambar 4.

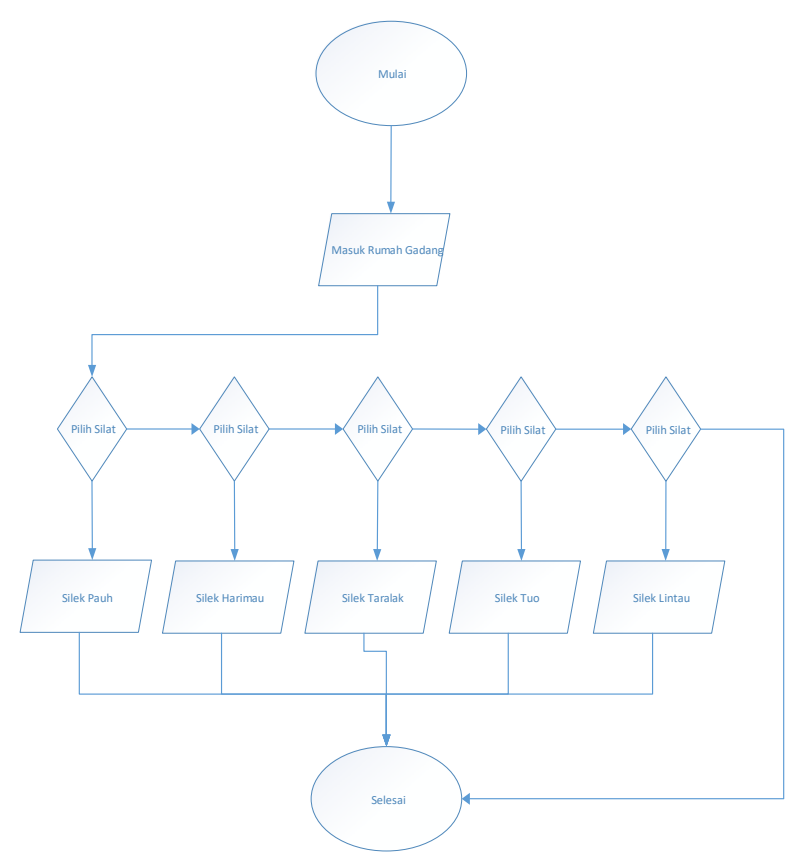

Gambar 4. Desain Flowchart Aplikasi

\section{Implementasi}

Aplikasi ini dibangun sebagai alat untuk menampilkan gerakan silat tradisional minangkabau dalam bentuk animasi 3D berbasis Virtual Reality, bentuk gedung objek lainya juga 3D, dimana bentuk 3D ini akan di gunakan pada smartphone dan di support dengan VR Glass.

\section{HASIL DAN PEMBAHASAN}

Hasil dari penelitian ini ialah aplikasi Virtual Reality yang menampilkan Gerakan silat tradisional Minangkabau dalam bentuk animasi 3-Dimensi. Pada bab ini akan ditampilkan tampilan aplikasi yang telah dibangun, hasil pengujian system, perawatan system.

\section{Tampilan Aplikasi}

Tampilan pertama pada aplikasi ini ialah splash screen. Splash screen ini merupakan tampilan pertama yang muncul sementara sebelum masuk ke menu utama ada aplikasi. Tampilan Splash screen dari aplikasi ini dapat dilihat pada Gambar 5.

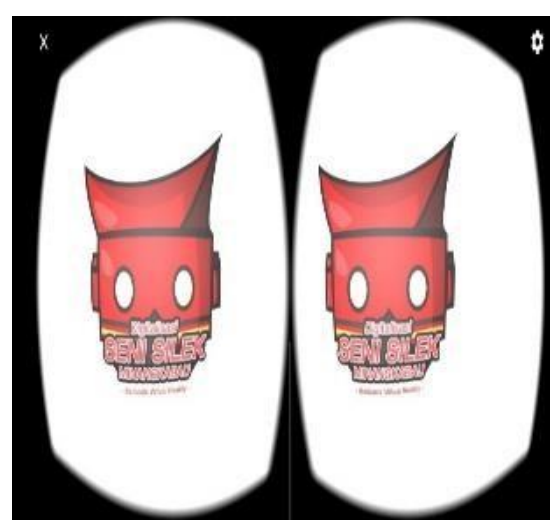

Gambar 5. Splash Screen Aplikasi

Splash screen pada aplikasi akan muncul selama beberapa detik, kemudian aplikasi akan menampilkan tampilan awal yang dapat dilihat pada Gambar 6.

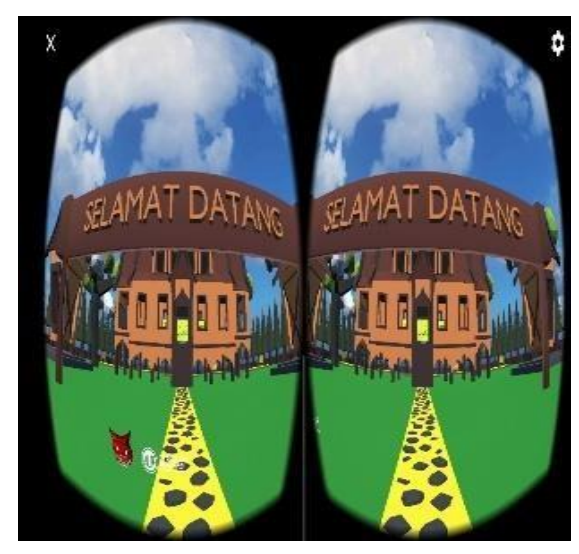

Gambar 6. Tampilan Awal Aplikasi

Selanjutnya halaman terakhir yang tampil pada aplikasi dan merupakan halaman utama ialah halaman yang menampilkan gerakan silat minangkabau. Pada halaman ini lah user dapat merasakan gerakan virtual dari silat minangkabau. 


\section{Pengujian Sistem}

Pengujian sistem yang dilakukan pada apikasi ini antara lain pengujian saat instalasi aplikasi, pengujian aplikasi dapat berjalan dengan baik, uji controller aplikasi, dan uji gerakan silat pada aplikasi. Hasil dari pengujian sistem ditampilkan pada Tabel 1

Tabel 1. Hasil Pengujian Sistem

\begin{tabular}{|c|c|c|c|}
\hline $\mathrm{NO}$ & PENGUJIAN & PROSES & HASIL \\
\hline 1 & $\begin{array}{l}\text { Penginstalan } \\
\text { aplikasi }\end{array}$ & $\begin{array}{l}\text { Proses instalasi } \\
\text { terpasang pada } \\
\text { smartphone } \\
\text { android dengan } \\
\text { baik }\end{array}$ & Berhasil \\
\hline 2 & $\begin{array}{l}\text { Aplikasi } \\
\text { Dapat } \\
\text { Berjalan }\end{array}$ & $\begin{array}{l}\text { Aplikasi berjalan } \\
\text { dengan baik di } \\
\text { smartphone } \\
\text { android yang } \\
\text { spesifikasinya } \\
\text { sudah di } \\
\text { tentukan }\end{array}$ & Berhasil \\
\hline 3 & $\begin{array}{l}\text { Controller } \\
\text { Dapat } \\
\text { Digunakan }\end{array}$ & $\begin{array}{l}\text { Android } \\
\text { Bluethoot } \\
\text { Controller dapat } \\
\text { digunakan } \\
\text { sebagai } \\
\text { controller bagi } \\
\text { user dalam } \\
\text { menjalankan } \\
\text { aplikasi }\end{array}$ & Berhasil \\
\hline 4 & $\begin{array}{l}\text { Gerakan Silat } \\
\text { Dapat } \\
\text { Berjalan } \\
\text { Dengan Baik }\end{array}$ & $\begin{array}{l}\text { Karakter 3D } \\
\text { yang sudah di } \\
\text { siapkan dapat } \\
\text { melakukan } \\
\text { gerakan silat } \\
\text { sesuai dengan } \\
\text { referensi yang } \\
\text { dijadikan } \\
\text { patokan }\end{array}$ & Berhasil \\
\hline
\end{tabular}

\section{Perawatan Sistem}

Pada tahapan ini dilakukan monitoring proses, evaluasi dan perubahan/ perbaikan apabila diperlukan. Perawatan
Software: Update software Unity dan Blender.

\section{SIMPULAN}

Berdasarkan Analisa dan pengujian pada aplikasi ini dapat disimpulkan.

a. Aplikasi ini sudah dapat mempermudah orang lain untuk mengenal dan mendapatkan informasi mengenai Silek Tradisional Minangkabau

b. Aplikasi ini sudah dapat memperlihatkan visualisasi dari gerakan Silek Tradisional Minangkabau

c. Aplikasi ini memberikan pengalaman lebih terhadap user dalam pengaplikasian belajar 'Elearning', karena aplikasi ini berbasis Virtual Reality.

d. Aplikasi ini kurang optimal pada saat terlalu banyak objek 3D yang di masukan ke dalam aplikasi.

\section{DAFTAR PUSTAKA}

[1] Irfan, D. (2013). Silek Harimau Minang Kabau : Ilmu Seni Bela Diri Sumatera Barat. Retrieved Agustus 30, 2020, from Traverse: https://traverse.id/budaya/silekharimauminangkabau-ilmu-seni-beladiri-sumaterabarat/@himsaifanah

[2] Liu, Q. (2012). The Virtual Reality Technology in Art Design.

2012 2nd International

Conference on Consumer

Electronics, Communications and Networks (CECNet), (pp. 22262228).

[3] Mihelj, M., Novak, D., \& Beguš, S. (2014). Virtual Reality Technology and Applications. London: Springer.

[4] Moura, F. T. (2017, March 16). Telepresence: The Extraordinary Power of Virtual Reality. Retrieved August 26, 2020, from Live Innovation: 
https://liveinnovation.org/telepresenc eextraordinary-power-virtual-reality/

[5] Muttelein, J. (2018). The Three Pillars of Virtual Reality? Investigating the Roles of Immersion,Presence, and Interactivity. Proceedings of the 51stHawaii International Conference on System Sciences, (pp. 14071415).

[6] Steuer, J. (1993). Defining Virtual Reality : Dimensions Determining Telepresence. Journal of Communication, 73-93. 